\title{
Deprotection of oximes using urea nitrate under microwave irradiation
}

\author{
P T PERUMAL*, M ANNIYAPPAN and D MURALIDHARAN \\ Organic Chemistry Division, Central Leather Research Institute, Adyar, Chennai 600 020, India \\ e-mail: ptperumal@hotmail.com
}

MS received 8 April 2004; revised 8 July 2004

\begin{abstract}
A new mild and efficient method for the cleavage of oximes to carbonyl compounds using readily available urea nitrate in acetonitrile-water $(95: 5)$, under microwave irradiation within 2 min, in good yields is reported.
\end{abstract}

Keywords. Deprotection; oximes; carbonyl compounds; urea nitrate; microwave irradiation.

\section{Introduction}

Oximes are readily prepared and stable $^{1}$ and are used for separation, purification and characterization of aldehydes and ketones. Several methods have been developed for the cleavage of oximes; they include acid catalysis, ${ }^{2}$ PCC, ${ }^{3}$ TBHP, ${ }^{4} \mathrm{I}_{2} / \mathrm{CH}_{3} \mathrm{CN},{ }^{5}$ manganese acetate/benzene, ${ }^{6}$ potassium peroxymonopersulfate, ${ }^{7} \mathrm{BiCl}_{3}{ }^{8}$ and $\mathrm{Zn}\left(\mathrm{BiO}_{3}\right)_{2} .{ }^{9}$ However, most of these reagents and the solvent systems used are toxic, corrosive or difficult to handle, especially on a large scale. With increasing environmental concerns, it is important that new 'environmentally friendly' reagents be developed using inexpensive and non-polluting materials.

Recently, urea nitrate has been used as an efficient catalyst for the imino Diels-Alder reaction, ${ }^{10}$ and nitration of carbazoles. ${ }^{11}$ Urea nitrate is readily prepared and is relatively insensitive to water. ${ }^{12}$ The use of microwave energy to activate organic reactions has been taking a new dimension recently. ${ }^{13-17}$ Herein we report the use of urea nitrate for the cleavage of oximes under microwave irradiation.

\section{Experimental}

\subsection{Materials, methods and instruments}

A BPL microwave cooking system model BMO700T, manufactured by BPL-SANYO utilities and appliances Ltd, Bangalore, India was used in the present studies. The oven has variable timing cycles

\footnotetext{
*For correspondence
}

from $1 \mathrm{~s}$ to $99 \mathrm{~min}$ and $99 \mathrm{~s}$ and heating cycles from 155 to $700 \mathrm{~W}$ of power output which can be varied by selecting power levels ranging from 10 to 100 . The overall dimensions of the domestic oven is $525(\mathrm{~W}) \times 419$ (D) $\times 281(\mathrm{H}) \mathrm{mm}$ with a chamber of $350(\mathrm{~W}) \times 370(\mathrm{D}) \times 208(\mathrm{H}) \mathrm{mm}$. The microwave frequency is $50 \mathrm{~Hz}$ and the oven capacity is 26 litres.

The products were characterized by GC-MS using a Perkin-Elmer Auto System XL Gas Chromatograph with a TurboMass Mass Spectrometer (EI, $70 \mathrm{ev}$ ), with helium as carrier gas at a flow rate of one $\mathrm{mL}$ per min, Perkin-Elmer Elite series PE-5, capillary column $(30 \mathrm{~m} \times 0.25 \mathrm{~mm} \times 1 \mu \mathrm{m})$, oven programmed between 100 and $260^{\circ} \mathrm{C}$ at the rate of $10^{\circ} \mathrm{C}$ per minute.

Analytical TLC was performed on pre-coated plastic sheets of silica gel G/UV-254 of $0.2 \mathrm{~mm}$ thickness (Macherey-Nagel, Germany). The products were purified by passing through a silica gel (60120 mesh; s.d Finechem Ltd, India) column eluted with 5-10\% ethyl acetate-petroleum ether.

IR spectra were recorded neat (for liquids) and $\mathrm{KBr}$ pellet (for solids) on a Perkin-Elmer Spectrum RXI FT-IR. ${ }^{1} \mathrm{H}$ NMR spectra were recorded on a Bruker instrument at $300 \mathrm{MHz}$ in $\mathrm{CDCl}_{3}$ and ${ }^{13} \mathrm{C}$ NMR spectra were recorded at $75 \mathrm{MHz}$ in $\mathrm{CDCl}_{3}$ with TMS as internal standard.

\subsection{Deprotection of oximes: General procedure}

4-Methylacetophenone oxime $(0 \cdot 3 \mathrm{~g}, 2 \cdot 2 \mathrm{mmol})$ and urea nitrate $(270 \mathrm{mg}, 2.2 \mathrm{mmol})$ were mixed together in acetonitrile-water $(95: 5,10 \mathrm{~mL})$ in an Erlenmeyer flask and placed in a BPL-SANYO domestic 
Table 1. Deprotection of oximes.

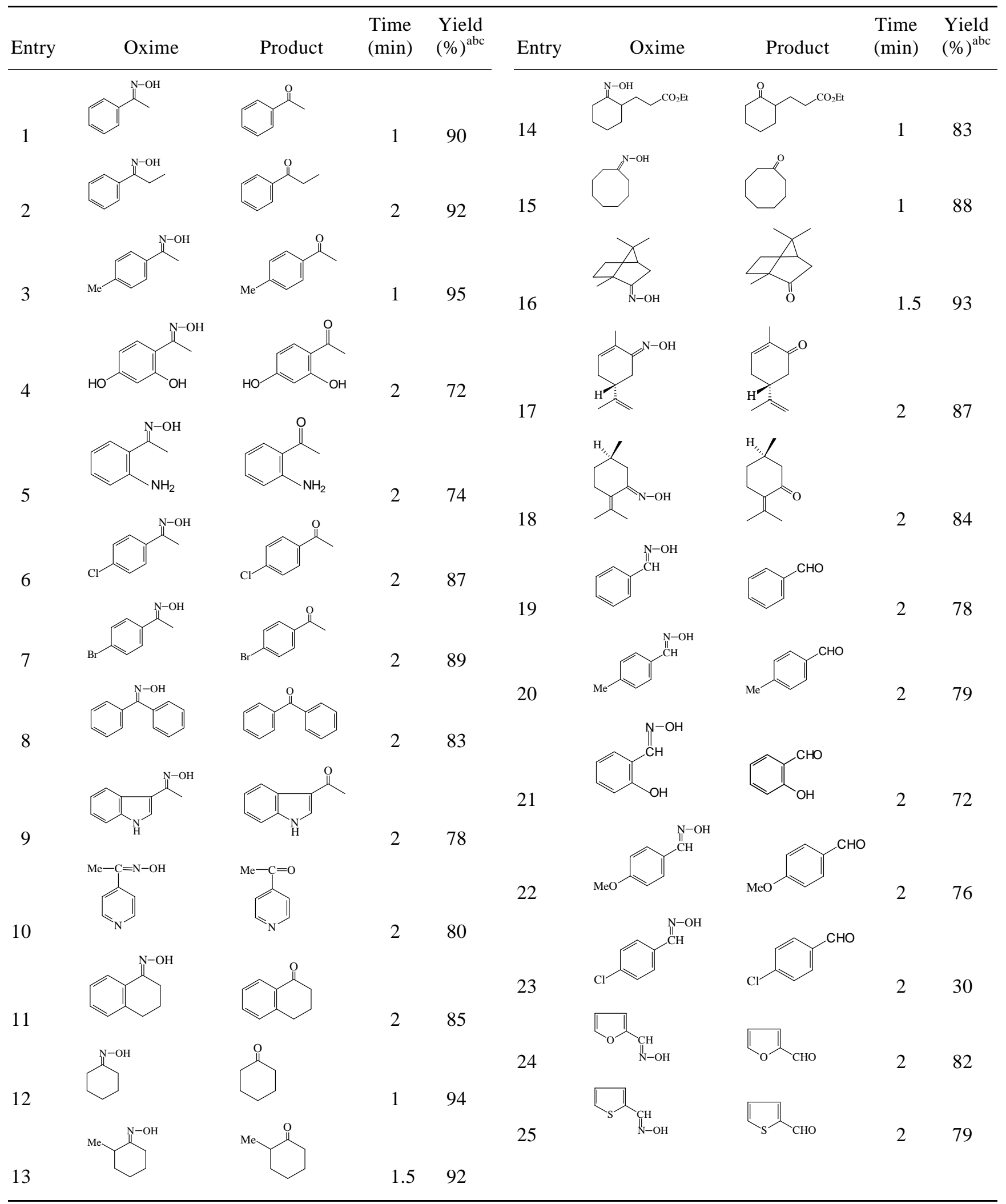

${ }^{\mathrm{a}}$ Refers to yields of isolated products

${ }^{\mathrm{b}}$ All the compounds obtained were characterized by IR, ${ }^{1} \mathrm{H}$ NMR, ${ }^{13} \mathrm{C}$ NMR, m.p. (for solids) GC-MS and comparison with authentic samples

${ }^{\mathrm{c}}$ Liquid compounds were obtained in mmol quantities. Hence boiling point not determined 
microwave oven operating at $80 \mathrm{~W}$, with a pulse of $10 \mathrm{~s}$ each for $1 \mathrm{~min}$. The reaction mixture was allowed to reach room temperature, treated with water and extracted with dichloromethane. After removing the solvent by distillation, the residue was purified by column chromatography on silica gel to give 4-methylacetophenone in $95 \%$ yield. There was no evidence for the formation of any side-product. Reaction under reflux condition for longer durations $(2-6 \mathrm{~h})$ resulted only in poor yield $(20-60 \%)$ in comparison to microwave irradiation conditions. All the compounds obtained were characterized by IR, ${ }^{1} \mathrm{H}$ NMR, ${ }^{13} \mathrm{C}$ NMR, m.p. (for solids), GC-MS and in comparison with authentic samples. ${ }^{18}$

\section{Results and discussion}

The deoximation reaction was carried out using one equivalent of urea nitrate in acetonitrile-water $(95: 5)$ and found to proceed efficiently in high yields within $2 \mathrm{~min}$. Thermal decomposition of urea nitrate produces $\mathrm{N}_{2} \mathrm{O}$ along with $\mathrm{CO}_{2}$ and water. ${ }^{19}$ This $\mathrm{N}_{2} \mathrm{O}$ may be promoting the cleavage of oxime to corresponding carbonyl compounds. ${ }^{20}$ The best results are achieved using aqueous acetonitrile as the solvent. The use of an inert atmosphere is not required for this reaction.

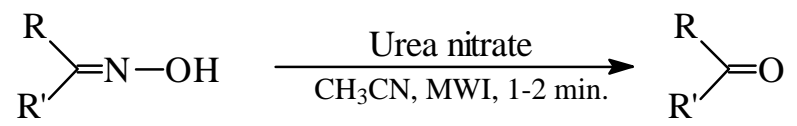

Results obtained (table 1) show that deprotection works well with a variety of aliphatic and aromatic ketoximes including sterically hindered oximes such as those of camphor, (R)-(-) carvone and (R)(+)pulegone (entries 16, 17, 18). In addition 2,4dihydroxy acetophenone, 2-amino acetophenone, 2-(carbethoxyethyl) propionate cyclohexanone and 2-hydroxy benzaldehyde oximes (entries 4, 5, 14, 21) undergo deprotection to give the corresponding carbonyl compounds smoothly without affecting the other functionality. Deprotection of substituted benzaldehyde oximes depends upon the substitution on the aromatic ring. Those bearing electron-donating groups such as $-\mathrm{CH}_{3}$ or $-\mathrm{OCH}_{3}$ as substituents (entries 20,22$)$ undergo catalytic cleavage smoothly to give the corresponding aldehydes. On the other hand, electron-withdrawing groups such as nitro or carboxyl substituents result in the recovery of un- changed oximes and very low yields of corresponding aldehydes (5\% and $10 \%$ respectively) under the same reaction conditions. 4-Chlorobenzaldehyde oxime gives only a $30 \%$ yield of 4-chlorobenzaldehyde (entry 23). Oximes of aliphatic aldehydes, cinnamaldehyde or phenylacetaldehyde as well as semicarbazones or hydrazones of aliphatic and aromatic carbonyl compound do not undergo the deprotection reaction.

In conclusion, a new but limited method for the deprotection of oximes to carbonyl compounds described in this paper provides further scope to the existing methods. The main advantages of this new method include the availability of inexpensive urea nitrate as the reagent, mild reaction conditions and reduced reaction time required for completion of reaction with excellent yields.

\section{Acknowledgement}

We thank the Council of Scientific and Industrial Research, New Delhi for financial support.

\section{References}

1. Greene T W P and Wuts P G 1999 Protective group in organic synthesis 3rd edn (New York: John Wiley and Sons) p. 214

2. Donaldson R E, Saddler J C, Byrn S, Mckenzie A T and Fuchs P L 1983 J. Org. Chem. 482167

3. Maloney J R, Lyle R E, Saavedra J E and Lyle G G 1978 Synthesis 212

4. Barhate N B, Gajare A S, Waharkar R D and Sudalai A 1997 Tetrahedron Lett. 38653

5. Yadav R D, Sasmal P K and Chand P K 1999 Synth. Commun. 293667

6. Demir A S, Taneyli C and Altinel E 1997 Tetrahedron Lett. 387267

7. Hajipour A R and Mahboubghah N 1999 Org. Prep. Proc. Int. 31112

8. Boruah A, Baruah B, Prajapati D and Sandhu J S 1997 Tetrahedron Lett. 384267

9. Firouzabadi H and Mohammadpoor-Baltork I 1994 Synth. Commun. 24489

10. Anniyappan M, Nagarajan R and Perumal P T 2002 Synth. Commun. 3299

11. Nagarajan R, Muralidharan D and Perumal P T 2004 Synth. Commun. 341259

12. Vogel A I 1971 A textbook of practical organic chemistry (London: Longmans) p. 442

13. Majdoub M, Loupy A, Peter A and Roudesli S 1996 Tetrahedron $\mathbf{5 2} 617$

14. Caddick S 1995 Tetrahedron 5110403

15. Raner K D, Strauss C R, Trainor R W and Thorn J S 1995 J. Org. Chem. 602456 
16. Baruah B, Boruah A, Prajapati D and Sandhu J S 1997 Tetrahedron Lett. 381449

17. Anniyappan M, Muralidharan D and Perumal $\mathrm{P} T$ 2002 Synth. Commun. 32659

18. Dictionary of organic compounds 4th edn 1965 (London: Eyre and Spottiswoode) p. 12, 23, 29, 80, 247,
247, 322, 348, 416, 543, 569, 593, 599, 785, 796, $1040,1046,1478,1941,2115,2168,2789,2881$, 3055,3075

19. Udupa M R 1982 Thermochim. Acta 55359

20. Adamopoulos S, Boulton A J and Tadayoni R $1987 \mathrm{~J}$. Chem. Soc., Perkin Trans 11 